\title{
Design of Participants Registration System for Training and Consulting Institution
}

\author{
Timotius Kevin, Fernaldi Kurniawan, Victor Sutiono, Vina Georgiana
}

\begin{abstract}
The rapid development information technology and the need for recognition of the workforce competencies, creating challenges for the growth of consulting and training institution. In this study, efforts will be made to improve participants registration system through the design of application. The author uses ITIL v3 problem management to analyze existing problems in the company and use the Object-Oriented Analysis and Design (OOAD) method in developing the systems. Data collection is done by conducting surveys, document studies, interviews and observations. The results of this study are a web-based registration system design that has the advantages of functional features, that is, Join Training, Invoice and Registration Status, where these three features will facilitate participants in registering, paying for and training placement. With the system developed, the registration process can run more effectively and efficiently than ever before and improve business operations at the institution.
\end{abstract}

Keywords: OOAD, ITIL V3 Problem Management, Registration Systems.

\section{INTRODUCTION}

In the era of technology, information is considered as an important asset for companies engaged in the field of Training \& Consulting. The availability of data and suggestions from participants can help companies engaged in the field to align their business processes according to the needs of participants. Effective data management can help companies to reach out directly to participants in terms of needs to their activities.

Commitment to the success of Training participants can be achieved through innovations such as flexible scheduling, online classes, digital libraries, online learning, computer simulations and online participant registration. This has been proven that training activities carried out online can make it easier for participants, and are more effective and more enjoyable than conventional systems that still rely on physical presence to conduct training activities. (Connors, 2007).

Revised Manuscript Received on February 28, 2020.

* Correspondence Author

Timotius Kevin, Information Systems Department, School of Information Systems, Bina Nusantara University, Jakarta, Indonesia, 11480. Email: pardedekevin@gmail.com

Fernaldi Kurniawan, Information Systems Department, School of Information Systems, Bina Nusantara University, Jakarta, Indonesia, 11480. Email: kwokaldi@gmail.com

Victor Sutiono, Information Systems Department, School of Information Systems, Bina Nusantara University, Jakarta, Indonesia, 11480. Email: victorsutiono@gmail.com

Vina Georgiana*, Information Systems Department, School of Information Systems, Bina Nusantara University, Jakarta, Indonesia, 11480. Email: vinageorgiana@binus.edu

(C) The Authors. Published by Blue Eyes Intelligence Engineering and Sciences Publication (BEIESP). This is an open access article under the CC-BY-NC-ND license http://creativecommons.org/licenses/by-nc-nd/4.0/
In companies engaged in the field of Training and Consulting, such as companies engaged in the same field, participants are registered to pursue the Training Certifications program within 3 (three) days, where 2 (two) days are training activities and 1 (one) day is an exam to achieve Certification, and participants must pass an exam to obtain certification from the company, provided that participants who take the training are expected to pay in full in order to get Certification if they pass.

\section{RESEARCH METHODS}

This research method uses quantitative and qualitative approaches for data collection, namely by conducting a questionnaire survey to trainees of companies engaged in the field of Training \& Consulting and conducting interviews with Sales Managers. For the analysis method will use ITIL v3 Framework Service Operation Problem Management. In this study, researchers distributed questionnaires using the Likert scale method from a scale of 1-6, ranging from disagreeing to strongly agreeing to 10 populations, consisting of 489 people who were training participants from January 2019 to April 2019. Then the researchers took a sample of 84 respondents from the Slovin formula $(n=489 / 1+4,89=84)$. The questionnaire aims to obtain information about the registration system that runs in the company, and problems with the registration system, as well as the satisfaction and needs of the company's customers. The technique for distributing questionnaires was done online using Google Docs, to 84 respondents. After the data is collected, then the data is analyzed using data processing techniques. Analysis of the data used by the authors in this study aims to answer the questions contained in the formulation of the problem. The data analysis method used is a statistical analysis method by conducting Validity and Reliability Tests with IBM SPSS Statistics 25 software. Then, the Researcher will conduct an interview with the Sales Manager to explore the company's business processes and find out complaints at the current registration service. The researcher establishes several criteria to determine the resource persons to match the problem and research objectives, as follows:

- Subjects have in-depth knowledge of companies engaged in the field of Training \& Consulting

- The subject is a manager-level sales person, who has had five years of work experience at the company.

\section{RESULT AND DISCUSSION}

\section{A. System Analysis}

After all data has been collected, the researcher will analyze the problem using ITIL V3 Problem management, 


\section{Design of Participants Registration System for Training and Consulting Institution}

in accordance with ITSMF (2010), which aims to prevent problems and incidents, eliminate the recurrence of incidents and minimize the impact of incidents that cannot be prevented.

\section{Data Collection ITIL V3 Problem Management}

ITSMF (2007) defines the five data collection with each understanding, namely, 1) Service Desk, where this data is obtained from problems or problems that have been recorded by the Service Desk Operator, then 2) Event Management, where the data is obtained from a database that is contains events and the data is then used for review. Then the third is 3) Incident Management, where it is centered on managing any incidents that occur in IT services, so that IT services for customers can immediately recover or return to normal conditions as soon as possible. Fourth 4) Proactive Problem Management where it is centered on a process to manage the root causes of IT service incidents so that these incidents do not occur again in the future and minimize the impact of incidents that cannot be prevented. Then the last is, 5) Supplier or Contractor, where it is centered on problems cannot connect to the Internet, because there is technical interference from the Network Provider.

In the Service Desk section researchers found no problems in this section, because reporting problems directly reported from participants to the sales concerned. Then the sales manager reports the incident directly to the IT Staff so that researchers do not do an analysis on the Service Desk.

In the Event Management section, researchers found that sales recorded data from participants manually using Microsoft Excel. It is recommended to use a database system that is the contact form 7 application on the company's website for automatic storage of participant data by the database.

In the Incident Management section, researchers found three incidents that could be improved as well as temporary solutions that could be provided : 1) Email: At present the company still uses the registration system via e-mail and the company e-mail often experiences overload, therefore the participant fails to send the registration form to the training due to the company's email overload. It is recommended to have a database to store all participant forms, and the database is obtained from the registration system through the website. 2) Website: Currently it has its own website but does not yet have a registration system, website visitors can only see the date, the training program to be held by the company, then the company profile, and the understanding of each training but cannot register through the website. It is recommended to provide features such as tracking status, brochures, view the schedule needed by website visitors and training participants. 3) Registration Procedure: Currently the company is still experiencing problems with registration procedure. Participants do not know what documents are needed for registration, there are no guidelines, and the registration fails due to an overload experienced by a company email. It is recommended that a registration system be established on the website that is currently running.

In the Proactive Problem Management section can not be done because the company does not have recurring data problems, but researchers conducted a formal interview to the sales manager to provide information related to the problem. that occur outside the company. For example, a company

From the results of the interview it can be concluded that internal parties do indeed need a registration system through a website or application that has features that aim to be useful for prospective participants and participants to register, view schedules and even choose schedules.

In the Supplier \& Contractor section it cannot be done because the company's internal parties conduct business processes independently and do not involve suppliers or contractors from outside the company.

\section{Problem Analysis ITIL V3 Problem Management}

After the five steps of data collection from ITIL V3 Service Operation Problem Management, it has been carried out and the data obtained is supportive. Then the researcher can analyze the problem using the three steps of ITSMF (2007) accompanied by supporting data, (1) Defining and grouping problems. Where this is the result of grouping problems that will later be used as assistance in solving a problem. on 2) Observing and diagnosing problems, it is centered on determining the cause of the problem, determining the impact of the problem and improving the status of the problem (Morris \& Liz, 2012), 3) Resolving the problem, where it is centered on the process of producing a solution that will be used in solving a problem problem happened. ITSMF (2007), Service Operation Problem Management, in the Problem Resolution \& Closure section defines that after being able to determine a solution, it should be ensured that the solution will not cause problems that can occur repeatedly.

Researchers get the problem findings from the analysis of the definition and grouping of problems:

- Participants do not know what documents are needed in the registration process. And there are supporting data from the questionnaire statement above, that as much as $96.4 \%$ of respondents agreed that there is a clear registration system, has guidelines and information for the registration process.

- Participants cannot see the training activities, see the schedule and view the brochure. In the statement there is supporting data from the questionnaire, that $95.4 \%$ of respondents agreed to need features to view the training program, brochures, and notifications.

- Participants fail to register via email. From the following statement there are supporting data from the questionnaire, that $44 \%$ of respondents had experienced a failure in registration.

- Not available brochure viewing feature, online registration feature, which makes it easy for participants to register online. From the above statement there are supporting data from the interview that the company already has its own website but does not yet have a registration system and features such as tracking status, viewing brochures, and schedules on its website.

After the researcher analyzes the problem definition and grouping, the researcher discovers the cause of the problem from the analysis results observing and diagnosing the problem:
Blue Eyes Intelligence Engineering \& Sciences Publication 
- Problems caused by company procedures, where it determines that participants must ask the admin directly by telephone, for documents of each type of training that are of interest, because there is no clear registration system and information related to training in an application or website. And the first problem is a problem that has a high level because it affects all business operations in the company and affects customer satisfaction. The problem is related to result 1.1 in the analysis of defining and grouping problems

- Problems in the absence of work instructions from the company to sales, in providing brochures, training schedules and status tracking. That is because in the jobdesk, every sales focus only on achieving sales targets, and if participants need the required documents, participants must ask the sales directly. The second problem is a problem that has a high level because it affects all business operations in the company and affects customer satisfaction. The problem is related to result 1.2 in the analysis section on defining and grouping problems

- The problem of corporate email overload where the problem is caused due to the absence of company procedures to the admin regarding special handling if the email is full. And another cause is, the admin only knows the full email, when participants fail to send the registration form to the admin. The third problem has a High level because it affects all business operations in the company and affects customer satisfaction. The problem is related to the results of analysis 1.3 namely defining and grouping problems

- Problems in the absence of online registration features, status tracking, brochure viewing, and schedules, where the problem is caused by the absence of company policy regarding the addition of online registration features, tracking status, brochure and schedule viewing, because promotions and sales are left to each salesperson. The last problem has a high level because it affects all business operations in the company and affects customer satisfaction.

After researchers find the cause of the problem, researchers can provide recommendations in the form of solutions that can improve the performance of companies engaged in the field of Training \& Consulting with the information below:

- Displays the training information contained in the brochure into the main page of the website, the website content is updated by the admin every time there is a new training schedule.

- Changing company procedures and policies to register online through the website.

- Designing an online registration system along with features for tracking status, and training schedules and connecting to the Contact Form 7 database on the company's website for training participation and data storage of participants who have registered for online training.

\section{B. System Design}

At this time the company already has a website but the registration system that is carried out is still done through email, therefore the registration system through the company's website is needed to facilitate customer. In the registration form section contains: first name, last name, phone number, e-mail, certification program to be followed, the time of training activities to be followed, the address of the customer, the required documents, and payment.

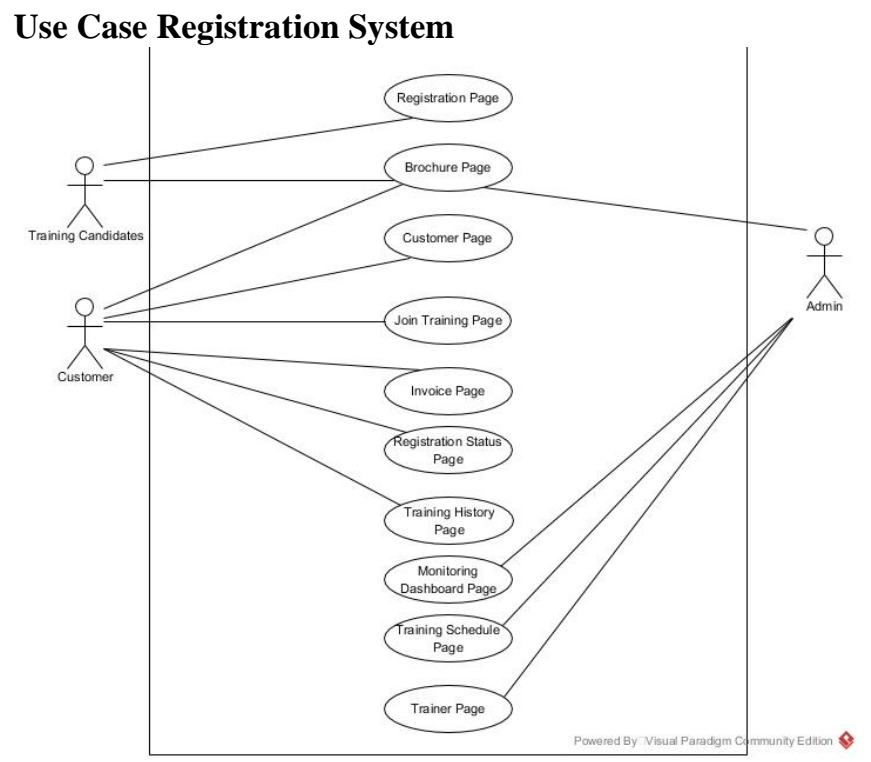

Fig. 1.Use Case Registration System

The design of the use case diagram of the registration system in companies engaged in the field of Training \& Consulting, there are 2 actors who are directly involved with the admin, prospective participants, customers. The following is an explanation of the use case that will be used for the company's website registration system.

- Use case page brochure diagram is done if the admin to create, read, update, or delete the training brochure on the brochure page, while for prospective participants, and customers can see the brochure they need to get information about the training they will follow .

- Use case page registration diagram conducted by prospective trainees to register training activities, and get a customer account on the website.

- A customer case diagram is used by the customer to change the personal data of the customer, view the training activities that have been followed, and register other training.

- Use case page invoice diagram is done by the customer to see the total training shares, and make training payments to get training registration status.

- Use case registration status diagram is carried out by prospective participants, and the customer by paying off the payment status before maturity is $2 \times 24$ Hours, which then the system will display and send the registration status to the customer.

- Use case page dashboard monitoring diagram conducted by admin to monitor registration of training activities which will then be stored for company records, input Customer training, and delete data from customers that are no longer needed by the company. 


\section{Design of Participants Registration System for Training and Consulting Institution}

- Use case page training schedule diagrams conducted by the admin to make training schedules that will be held by the company, and to make changes if there is an error in inputting the training schedule.

- Use case page trainer diagrams conducted by the admin to enter trainers or trainers and schedules for trainers.

\section{Class Diagram Registration System}

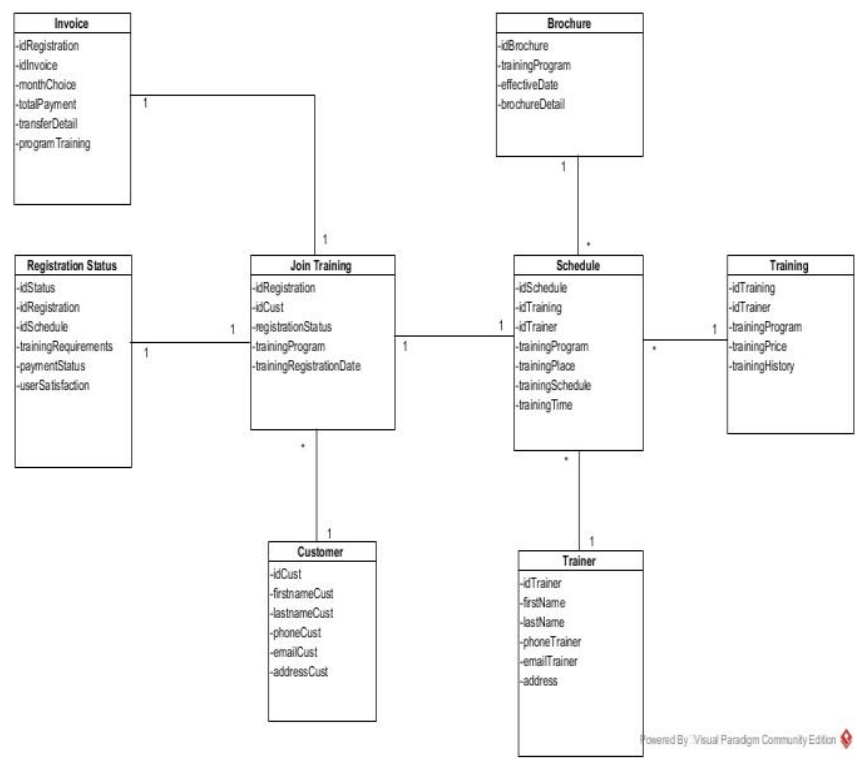

Fig. 2.Class Diagram Registration System

\section{User Interface}

\section{Form Registration}

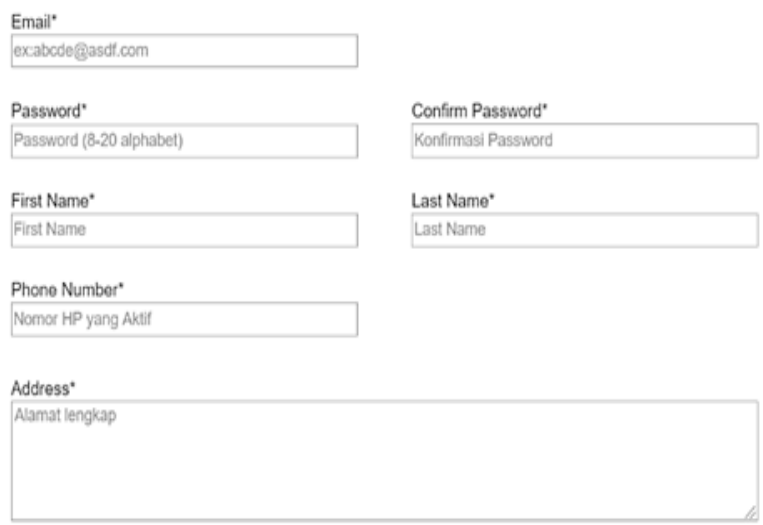

SUBMIT NOW

Fig. 3.Registration Page

Participants can fill in the registration form which contains the participant's personal data such as Customer ID, password, and password confirmation for the login, phone number, email, and full address of the prospective participant. After all data is correctly filled, the system will store customer data which will later be used to login to the customer's page.

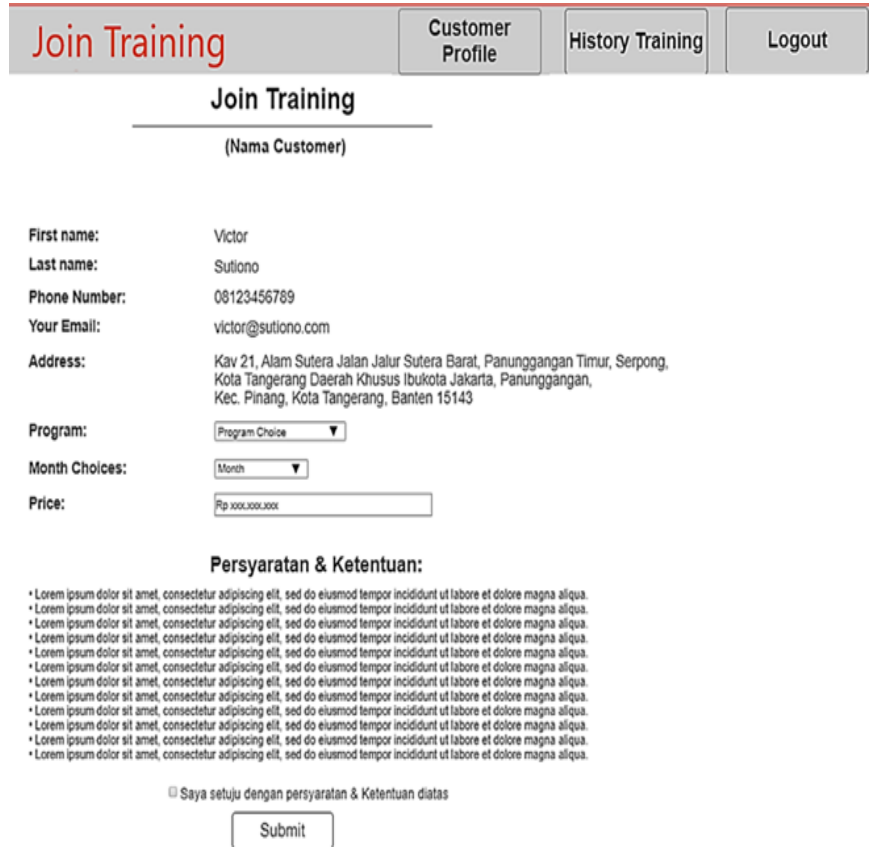

Fig. 4.Join Training Page

On the join training page, customers can participate in training activities, and customers can choose the program to be followed and the desired activity time.

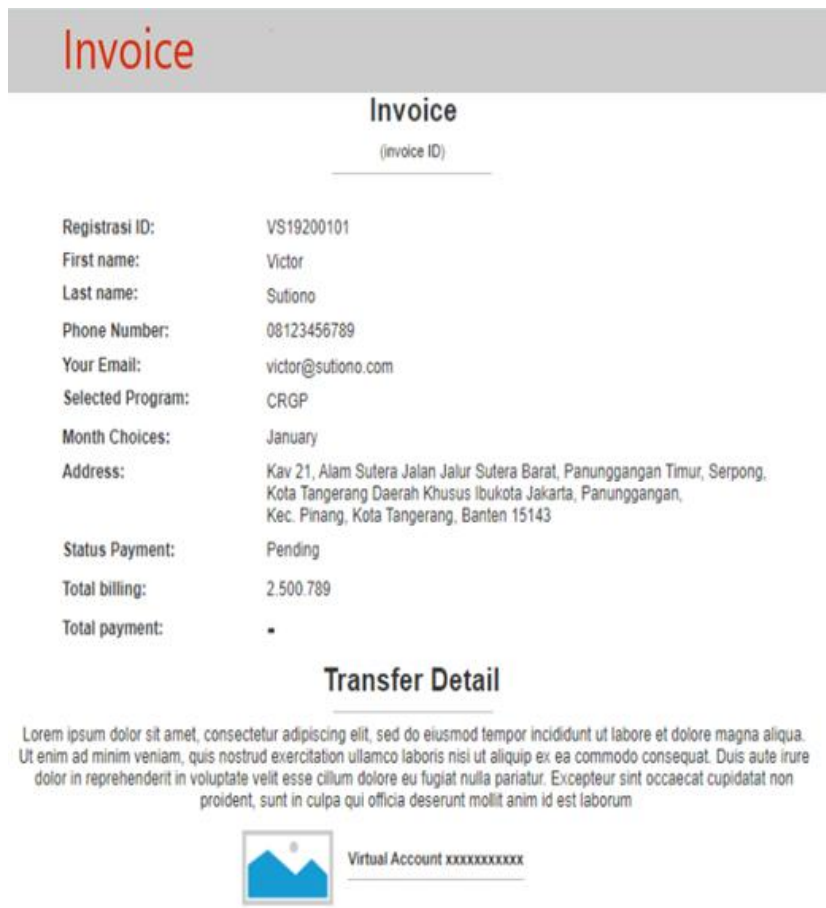

Fig. 5.Invoice Page

The invoice page will appear when you press the submit button on the Join Training page and will later be directed to this page, the customer is also given an invoice form via email in the form of a link containing the personal data during registration and the payment amount, payment is made through a virtual account provided by the system and payment will be given a deadline of 2x24 hours for each transaction. 


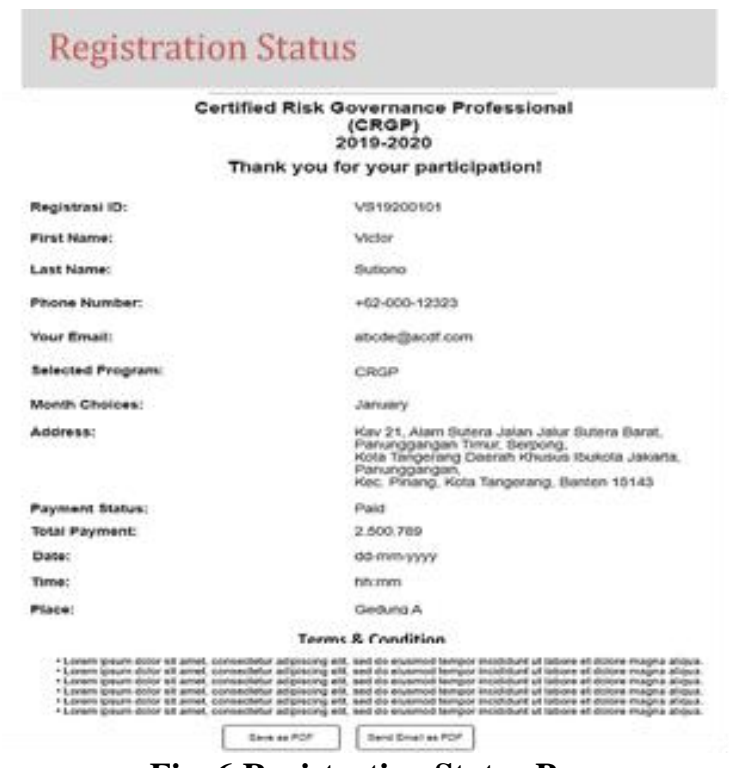

Fig. 6.Registration Status Page

Training registration status is obtained by the customer after making a payment which will then be sent to the customer's email, this registration contains data about customer data that will participate in the activities or participation in training, in this form also contains the place, training schedule, terms and conditions must be taken during training.

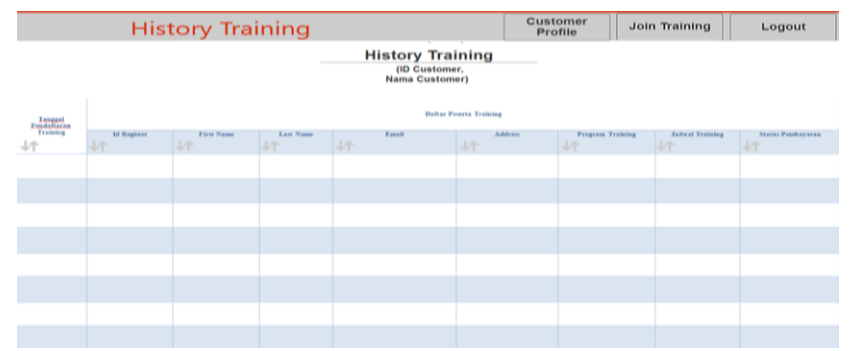

Fig. 7.History Training Page

On this page the customer can see the training activities that have been followed.

\section{CONCLUSION}

Based on the analysis and design of a web-based registration system in the field of Training \& Consulting, the conclusions can be drawn as follows:

a) Participants registration systems can be applied in the field of Training and Consulting Institution. The institution need to immediately change the business operations to compete with companies in the same field. The special instructions and training for the admin and participants in conducting online registration system are also required to make sure the system will be applied correctly.

b) Researchers found that there were some problems in the conventional registration system, namely, the absence of information regarding the requirements and documents needed to register for training participation, the number of registrations that failed due to full email to the company. The registration process for prospective participants and companies can be more effective to be overcome by designing a web-based registration system c) The registration system design can provide benefits for companies and prospective participants who will participate in training activities, include companies can monitor the training held, prospective participants can choose a schedule directly, payment is verified automatically by the system, the registration status can be known at any time, and the registration system that is designed also speeds up the process of registering training activities at Training and Consulting Institution.

\section{REFERENCES}

1. C.E Walker, E. Kelly, Online Instruction: Student Satisfaction, Kudos, and Pet Peeves, Quarterly Review of Distance Education, 8(4), 2007, p309-319

2. D.L. Ralph, B.D Buskirk, and S.M.P Schimdt, Online Projects VS the 3 Ring Binder: A Case Study, The Business Review, Cambridge, 9, 2007, pp. 106-111

3. http://www.studymode.com/essays/Thesis Proposal-1146036.html, 2012. Accessed 27/09/2019

4. ITSMF. (2007). Foundations of IT Service Management Based on ITIL V3. English: Van Haren Publishing, Zaltbommel, www.vanharen.net.

5. J.A O'Brien and GM.Marakas, Introduction to Information Systems, 13th edition. New York, Prentice Hall, 2007

6. K.C Laudon and J.P. Laudon, Fundamentals of business Information systems, 7th edition, New York, Prentice Hall, 2007.

7. M. Bugeja, Distractions in the Wireless Classroom, Chronicle of Higher Education, 53, 2016.

8. Morris, H., \& Liz, G. (2012). ITIL Foundation Exam Study Guide. United Kingdom: Jhon Wiley \& Sons, Ltd.

9. Rajapakse, C. Damith, A Fresh Graduate Guide to Software Development Tools and Technologies(Chapter 7 - Web Development Pg 4), 2012 edition, National University of Singapore, 2007.

10. S. Connors, 21st Century Tools, Phi Delta Kappan, 89, 320, 2007.

11. S. Hale, Being Online, Academe , 93, 2007

12. T. Isakowitz, M. Bieber, and F. Vitali, Web Information Systems, Communications of the ACM , 41(7), 78-80, 1998.

13. W. J. Kramer, B. Jenkins, and R. S. Katz, The Role of the Information and Communications TechnologySector in Expanding Economic Opportunity, Corporate Social Responsibility Initiative Report No. 22,Cambridge, MA: Kennedy School of Government, Harvard University, 2007.

\section{AUTHORS PROFILE}

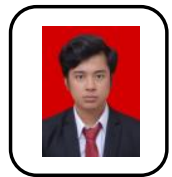

Timotius Kevin, is an undergraduate student at the School of Information Systems, Bina Nusantara University, Indonesia.

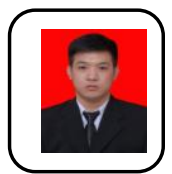

Fernaldi Kurniawan, is an undergraduate student at the School of Information Systems, Bina Nusantara University, Indonesia.

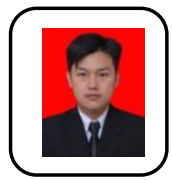

Victor Sutiono, is an undergraduate student at the School of Information Systems, Bina Nusantara University, Indonesia.

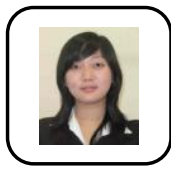

Vina Georgiana, is a lecturer at the School of Information Systems, Bina Nusantara University, Indonesia. She obtained her bachelor's degree in Information Systems and a master's degree in Management. Her teaching experience for undergraduate students is in the field of information system analysis and design, management information systems, and user experience. 